\title{
Optimization of Welding Speed Using Mahalanobis Distance Method on a Vertical-Position Welding Process
}

\author{
Khairul Muzaka, Min-Ho Park, Jong-Pyo Lee, Byeong-Ju Jin, Do-Hyeong Kim and Ill-Soo Kim \\ Department of Mechanical Engineering, Mokpo National University, 61, Dorim-ri, Chungkye-myun, \\ Muan-gun, Jeollanam-do 534-729, Republic of Korea \\ *Corresponding author: Tel: +82-61-450-2416, Fax: +82-61-452-6376 \\ zakita17s@gmail.com
}

\begin{abstract}
For the automation of complex manufacturing systems, a great deal of progress came up precision and on-line quality control. However, the welding process for the vertical-position is not only much more difficult, but also has tendency that the welding quality is lower compared to a horizontal-position welding because the effect of gravity force on metal transfer during welding process could cause to the welding fault. The common method in detecting of the welding fault has still been based on off-line technique whereas the weld fault could be detected after the welding process finished, and hence, it leads to inefficient process. In order to deal with that challenge, a new algorithm based on Mahalanobis Distance (MD) method for an on-line monitoring system for the vertical-position welding process is proposed in this study. From the results, it was found that the optimal welding speed setting at $53 \mathrm{~mm} / \mathrm{min}$ has obtained the highest welding quality whereby the welding quality $98.01 \%$ of the start position and $99.36 \%$ of the middle position. The verified results confirmed that the developed algorithm could be defined the welding quality so that it is useful method to be applied for welding control system to achieve the desired welding quality.
\end{abstract}

Keywords: Vertical-position welding, Welding speed, Welding quality, Welding fault, On-line monitoring system, Mahalanobis distance.

\section{Introduction}

The welding process is joining process that widely used in many engineering application which is difficulty replaced by other method. For example, the ship building is one of many applications of the welding process applied in engineering field. Until now, the welding method to join the plate of outer ship body still couldn't be changed by other joining method. Another application of the welding process is in large steel structures which need high tensile strength. The strength of the weld is influenced by the welding quality whereas the high quality of the weld has the welding strength similar with specification of the desired strength. Technology advancements seek to meet the demands for quality and performance through product improvements and cost reductions.

The welding quality is affected by the welding speed which is defined as the electrode travel rate along the seam or travel rate of the work under the electrode along the seam. In addition, the welding speed has significant effect to production improvement, by increasing the travel speed and maintaining constant welding current. Furthermore, increasing the welding speed in arc welding process will cause decreasing in the heat input, the weld per unit length and the weld reinforcement as the welding quality. [1], so that the welding speed has significant effect to the welding quality. Moreover, the quality of welding is not just affected by the welding speed, but the welding position has important role to determine the welding quality during the welding process. The horizontal-position welding process generally produces better welding quality that of the vertical-position welding process. It could happen because the gravity force on the vertical-position welding affects the metal transfer during the welding process. Therefore, it is much more difficult to control welding quality for the verticalposition welding than the horizontal-position welding.

Currently, the welding fault detection still based on the off-line detection method which leads to decreasing in productivity and also the welding quality couldn't be controlled during the welding process. It could happen because the welding fault detection is only done after the welding process finished. Therefore, the application of the on-line welding fault detection method is very important to achieve good quality of the weld as well as increasing the productivity. Additionally, 
the welding control system uses the optimal welding parameters during the welding process as a feedback to manipulate the welding quality.

The optimal welding parameters could be achieved the efficient welding process which lead to low labor intense, time saving as well as production cost reduction. Because of those advantages, the optimal welding parameters might be applied in a welding automation system. Until now, good welding process with the experienced and fast welding speed that produces from high degree welding automation system have widely been applied [2-8]. The welding automation system has many challenging issues among others: accurate seam tracking, precise pipeline alignment and welding parameters optimizing [9]. The welding quality generally indicated by bead geometry which is affected by the input energy dissipation, as well as the distribution and amount of input energy on the workpiece area [10]. Increasing the welding quality and reducing production cost could be achieved by applying the automatic on-line welding quality monitoring system [11]. Therefore, it is very important to control the welding process by implementing the automatic on-line monitoring system. Recently, controlling system and real-time welding quality could be applied to ensure the welding quality as well as to avoid the welding fault on the work surface [12]. The transformed arc voltage and welding current from on-line monitoring system are analyzed to quantify the welding quality.

There are a few studies that examined the transformed arc voltage and welding current from on-line monitoring system to detect welding faults. Li and Simpson [13] used parametric approach to detect fault position in short arc. Adolfsson et al. [14] have studied the prediction of welding quality based on arc voltage variance. MD was developed by Mahalanobis, an Indian famous statistician in 1936 which is a robust and simple method. There are many studies on welding quality quantified from the welding faults based on MD theory [10-12, 15]. Feng et al. [11] performed to find the welding fault by qualitative quantities analysis in GMA (Gas Metal Arc) welding process using MD. Arc voltage and welding current analyzed to determine the welding quality by quantified the welding fault on overlay pipeline welding process used MD method [10]. Muzaka et al. [16] studied welding quality on the vertical-position welding process by calculating the welding fault. The reviewed literatures [10-15] mostly limited on investigation of welding fault to quantify the welding quality on the horizontalposition welding.

Therefore, this study takes into consideration of the development of a new algorithm to select optimal welding speed using MD method on the vertical-position welding process by analyzing the transform arc voltage and welding current gained from the on-line monitoring system. The transformed welding current and arc voltage data were taken from the experiment whereby the data number was $2500 \mathrm{data} / \mathrm{s}$. The prediction of welding speed to gain best welding quality using the waveform variations were taken from the experimental results. MD was employed to quantify the welding quality by analyzing the transformed arc voltage and welding current. Finally, the optimal welding current setting has verified the developed algorithms through additional experiments.

\section{Experimental Procedures}

In order to calculate welding quality in this study, sequence experiments conducted bead-on-plate GMA welding process with the vertical-position using SS400 steel plates of size 40x40x10 $\mathrm{mm}^{3}$. The chemical compositions of base metal and filler wire are presented in Table 1. The shielding gas was used $\mathrm{CO}_{2}$, and constant current power source has been applied. Sheets of steel were cleaned using steel wire brush continued by acetone swabbing just before to welding, and followed by bead-on-plate GMA welding process [17]. Figure 1 shows setting up the equipment of the experiment, followed by positioned the steel plate vertically which held in fix jig to minimize the welding distortion during the welding process as shown in Figure 2.

Table 1: Chemical compositions for base metal \& filler wire.

\begin{tabular}{|c|c|c|c|c|c|c|c|c|}
\hline \multirow{2}{*}{ Material } & \multicolumn{9}{|c|}{ Element Weight (\%) } \\
\cline { 2 - 9 } & $\mathrm{C}$ & $\mathrm{Si}$ & $\mathrm{Mn}$ & $\mathrm{Ti}$ & $\mathrm{P}$ & $\mathrm{S}$ & $\mathrm{Al}$ & $\mathrm{Zr}$ \\
\hline Base metal (\%) & 0.17 & 0.54 & 1.40 & 0.07 & 0.045 & 0.045 & - & - \\
\hline Filler wire (\%) & 0.07 & 0.54 & 1.18 & 0.07 & - & - & 0.08 & 0.05 \\
\hline
\end{tabular}

The welding inverter was set manually for the arc voltage and welding current which is measured during the welding process using the digital data acquisition system. The experimental data was recorded using a specifically designed power 
supply. To establish adequate operating condition during the welding process, it performed initial trials before the experiment. The electrode moved downward direction during GMA welding process which programed the welding speed. The experimental design is shown in Table 2 which used three different setting of welding speed.

Table 2: Experimental design.

\begin{tabular}{|l|c|c|}
\hline \multicolumn{1}{|c|}{ Parameter } & Value & Unit \\
\hline Contact Tip to Work Distance (CTWD) & 15 & $\mathrm{~mm}$ \\
\hline Electrode angle & 75 & $\mathrm{o}$ \\
\hline Arc voltage & 23 & $\mathrm{~V}$ \\
\hline Welding current & 250 & $\mathrm{~A}$ \\
\hline Gas Flow rate & 18 & $\mathrm{I} / \mathrm{min}$ \\
\hline Welding Speed & $47,53,60$ & $\mathrm{~cm} / \mathrm{min}$ \\
\hline
\end{tabular}

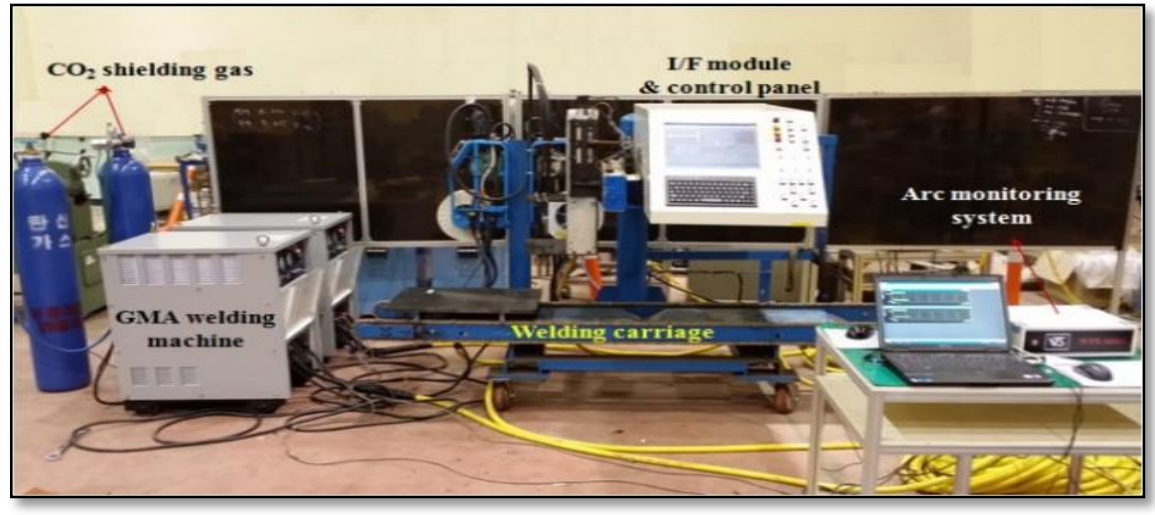

Fig. 1: Overview of experimental setup.

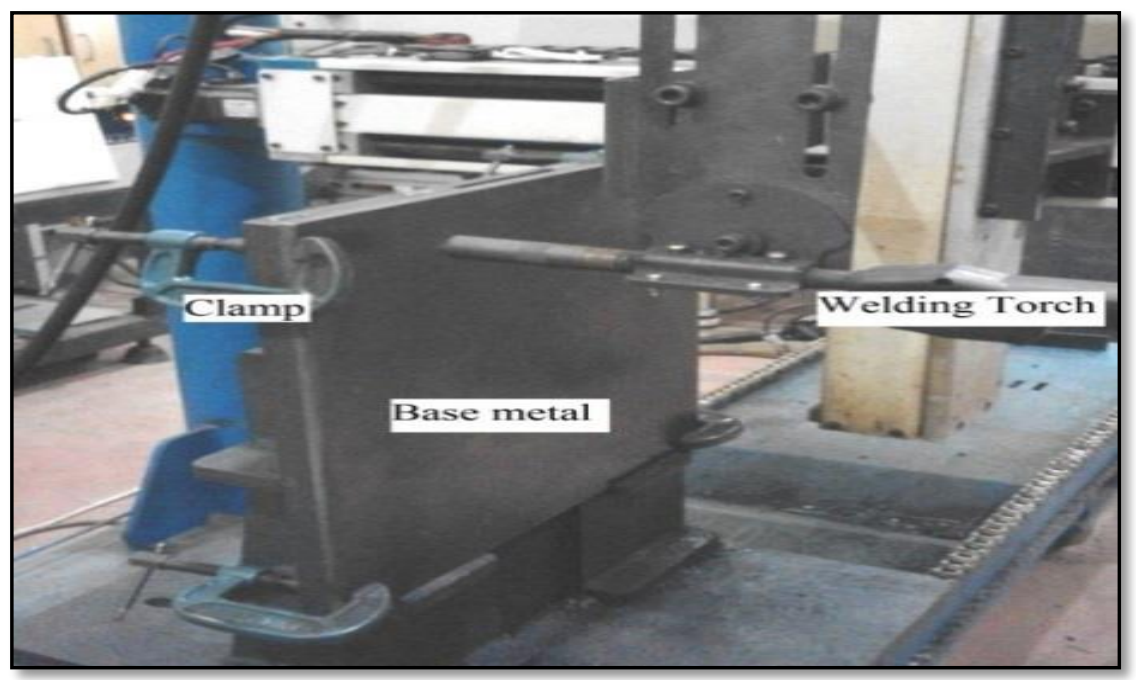

Fig. 2: Welding fixture of base metal and welding torch.

MD has been employed to analyse the transform welding current and arc voltage which taken during the experiment to get the welding quality. The welding quality was gained by quantifying the number of welding fault per second. There are few steps to determine the welding fault; first step is setting up the MD threshold value $(\sigma)$. Second step, the welding fault is determined using threshold value $3 \sigma[10]$, Third step, calculate the welding fault in every $0.25(\mathrm{~s})$. Finally, the quality for the vertical-position welding could be determined by calculating the welding fault percentage. 


\section{Results and discussion}

\subsection{Development of optimal algorithm for welding speed setting}

To carry out the experiment, the specimens were prepared in Figure 3 which indicated the measured position to determine the optimal welding speed by quantifying the welding quality. There were two sections gained from the specimen (the start section and the middle section) that indicated by marked 1 and 2 respectively.

The experimental data were selected 2 seconds after the start for the start section and the middle section at 11 seconds after the start, since welding quality at base metal are generally unstable for the initial and the end section area [12, 13]. The reference was used the experimental data from the start position of each welding speed setting whereas the quality quantified in every 0.25 second.

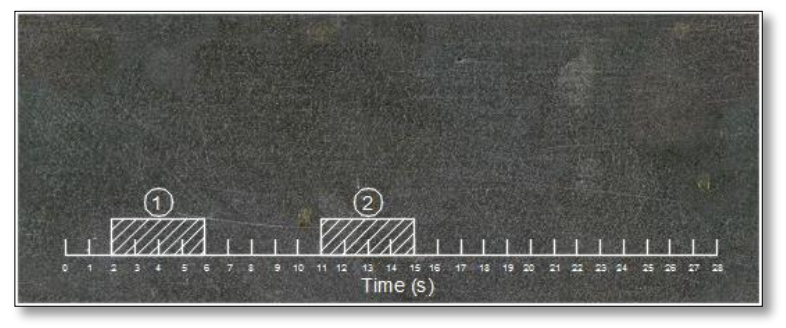

Fig. 3: Measured position on weld base metal during welding process.

Figure 4(a) shows the waveform of arc voltage at the start position of welding speed setting at $47 \mathrm{~mm} / \mathrm{min}$ has many fluctuations in wave length, the fluctuation occurred mostly around $0.25(\mathrm{~s})$ to $3(\mathrm{~s})$ which is the fluctuation in wave length due to decreasing of the arc voltage. From the Figure 4(b), it can be observed that the waveform of welding current also has many fluctuations in wave length from about $0.25(\mathrm{~s})$ to $2.75(\mathrm{~s})$ continued stable up to $4(\mathrm{~s})$. The fluctuations of welding current in wave length happened due to increasing the welding current. Figure 4(c) shows the arc voltage waveform of the middle position of welding speed setting at $47 \mathrm{~mm} / \mathrm{min}$ has lesser fluctuations in wave length compared the arc voltage at the start position that showed in Figure 4(a). The fluctuations in wave length mostly occurred from 2(s) to 2.5(s). The waveform of the welding current of the middle position of welding speed setting at $47 \mathrm{~mm} / \mathrm{min}$ that showed in Figure $4(\mathrm{~d})$ indicated less fluctuations in wave length which accumulated around 2(s) to 2.5(s) and also much more stable compared to the welding current at the start position shown in Figure 4(b).

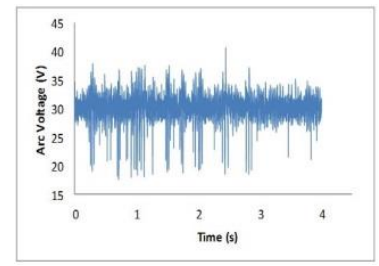

(a) Start position

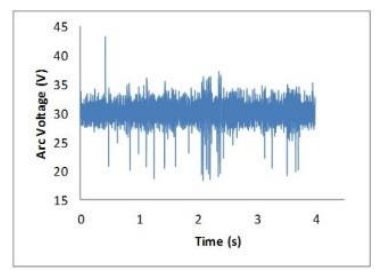

(c) Middle position

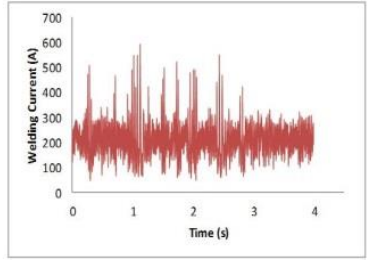

(b) Start position

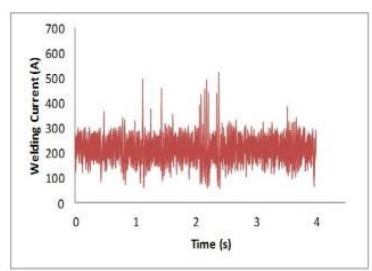

(d) Middle position

Fig. 4: Arc voltage and welding current waveform of welding speed setting at $47 \mathrm{~mm} / \mathrm{min}$.

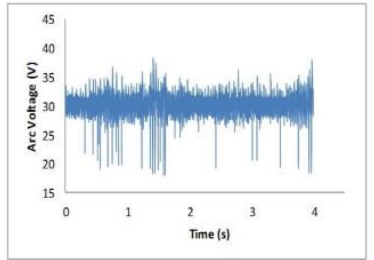

(a) Start position

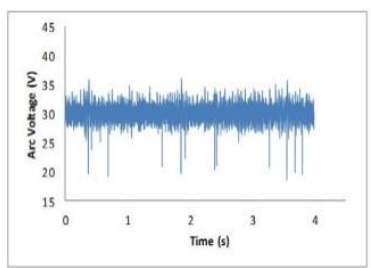

(c) Middle position

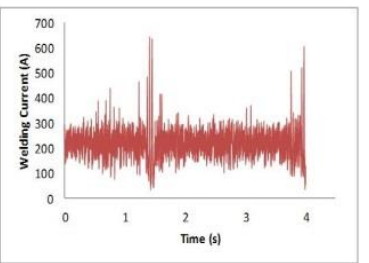

(b) Start position

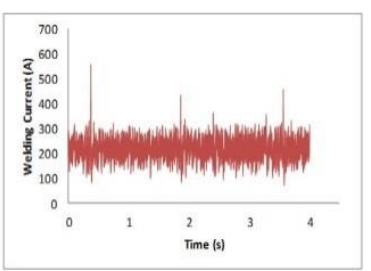

(d) Middle position
Fig. 5: Arc voltage and welding current waveform of welding speed setting at $53 \mathrm{~mm} / \mathrm{min}$.

There are many fluctuations in wave length of arc voltage waveform at the start position of welding speed setting at $53 \mathrm{~mm} / \mathrm{min}$ shown in Figure 5(a), whereas the most fluctuations happened from 0.25(s) to 1.75(s) and from 1.25(s) to 1.50(s). 
Also it can be observed that the fluctuation in wave length has tendency to downward direction or decreases in the transformed arc voltage. Figure 5(b) shows waveform of welding current at the start position of welding speed setting at 53 $\mathrm{mm} / \mathrm{min}$ which is the highest fluctuation in wave length occurred around 1.25(s) to 1.75(s) and 4(s). Figure 5(c) indicates the arc voltage waveform of the middle position of welding speed setting at $53 \mathrm{~mm} / \mathrm{min}$ confirmed much more stable compared to arc voltage at the start position (Figure 5(a)) with little fluctuations in wave length spread during the welding process. Figure 5(d) represents welding current waveform at the middle position of welding speed setting at $53 \mathrm{~mm} / \mathrm{min} \mathrm{had}$ few fluctuations in wave length which is more stable compare to welding current waveform at the start position in Figure $5(b)$.

Figure 6(a) presents the stable waveform of arc voltage at the start position with small amount of fluctuations in wave length whereas spreaded during welding process about 1(s) to 3(s). The waveform of welding current at the start position of welding speed setting at $60 \mathrm{~mm} / \mathrm{min}$ has the uniformed shape with 2 fluctuations in wave length which happened around $1.25(\mathrm{~s})$ and 2.75(s), as shown in Figure 6(b) that the waveform is very stable.

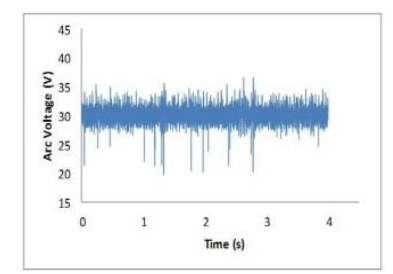

(a) Start position

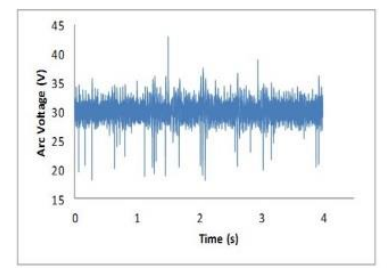

(c) Middle position

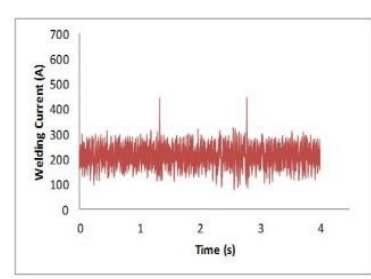

(b) Start position

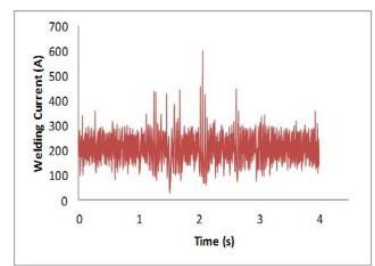

(d) Middle position

Fig. 6: Arc voltage and welding current waveform of welding speed setting at $60 \mathrm{~mm} / \mathrm{min}$.

Figure 6(c) indicates the arc voltage waveform at the middle position of welding speed setting at $60 \mathrm{~mm} / \mathrm{min}$ fluctuated in wave length during the welding process and more fluctuations compared to the arc voltage waveform at the start pasition in Figure 6(a). The welding current waveform at the middle position of welding speed setting at $60 \mathrm{~mm} / \mathrm{min}$ has many fluctuations which spread around 1.25(s) to 2.75(s) shown in Figure 6(d). The welding current waveform at the middle postion in Figure 6(d) has much more fluctuation in wave length compared to the waveform of the welding current at the start position in Figure 6(b). From the observation, it could be found that both arc voltage and welding current waveform at the start position has more stable compared to those of the arc voltage and welding current at the middle position. It could be observed from the Figures 4-6 that the arc voltage waveform fluctuations in wave length occurred due decreasing of the transformed arc voltage, and in converse, the welding current waveform fluctuations in wave length due to increasing the transformed welding current.

Figure 7(a) shows comparison of welding quality among three different setting of welding speed at the start position. It could be observed that the lowest quality value of welding speed setting at $47 \mathrm{~mm} / \mathrm{min}$ is $87.68 \%$ at 1.25 (s) with the average quality is $96.68 \%$. The lowest quality of the welding speed setting at $53 \mathrm{~mm} / \mathrm{min}$ is $87.84 \%$ at $1.5(\mathrm{~s})$ whereby the average quality is $98.01 \%$. And then the welding speed setting at $60 \mathrm{~mm} / \mathrm{min}$ has the lowest quality $94.72 \%$ at 3(s) and for the average quality is $98.97 \%$.

The welding quality of three different welding speeds setting at the middle position is shown in Figure 7(b). It was clearly indicated that the quality of welding speed setting at $47 \mathrm{~mm} / \mathrm{min}$ has lowest quality $89.44 \%$ at $2.25(\mathrm{~s})$ which average quality is $98.39 \%$. The quality of welding speed setting at $53 \mathrm{~mm} / \mathrm{min}$ has lowest quality $96.64 \%$ at $0.5(\mathrm{~s})$ whereas the average quality is $99.36 \%$. The lowest quality of welding speed $60 \mathrm{~mm} / \mathrm{min}$ setting is $89.92 \%$ at $2.25(\mathrm{~s})$ with the average quality is $98 \%$. 


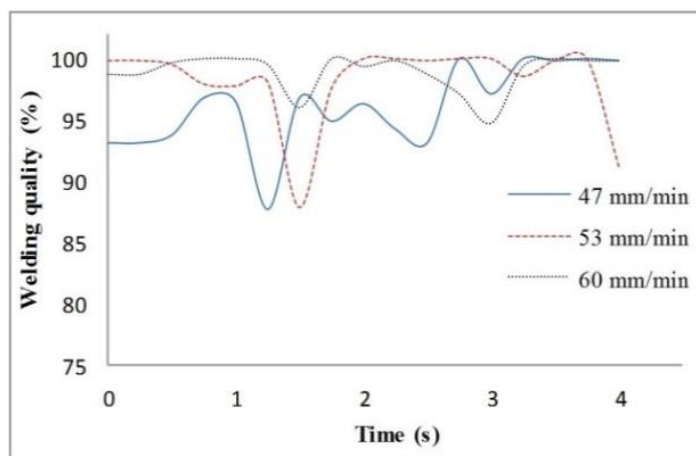

(a) Start position

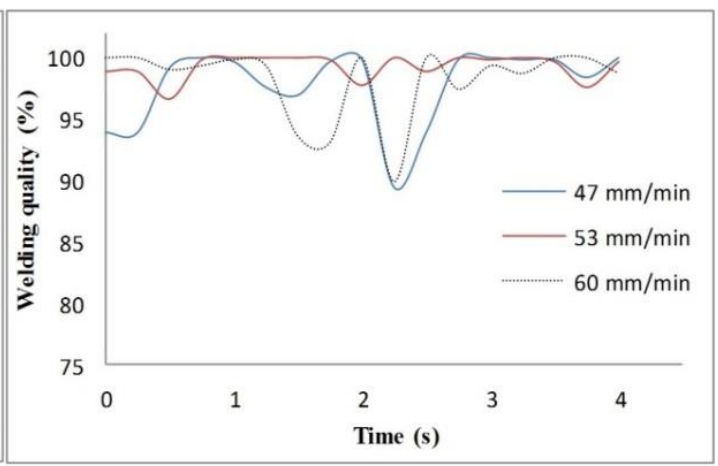

(b) Middle position

Fig. 7: The comparison of welding quality among welding speed at 47, 53, $60 \mathrm{~mm} / \mathrm{min}$.

Figure 8 shows the comparison of welding quality of three different welding speeds setting at the start and middle positions. It could be observed that the average welding qualities of the start and middle positions of welding speed at 47 $\mathrm{mm} / \mathrm{min}$ are $96.68 \%$ and $98.39 \%$ respectively. It also can be observed that average of welding qualities of the start and middle positions of welding speed at $53 \mathrm{~mm} / \mathrm{min}$ are $98.01 \%$ and $99.36 \%$ in series. Finally, the average of welding qualities of the start and middle position of welding speed setting at $60 \mathrm{~mm} / \mathrm{min}$ are $98.97 \%$ and $98 \%$. From the Figure 8 , it is confirmed that the welding speed at $53 \mathrm{~mm} / \mathrm{min}$ has increased the welding qualities from the start to the middle positions, and it also has higher quality compared to those two others even though the quality of the start position is below the welding speed setting at $60 \mathrm{~mm} / \mathrm{min}$.

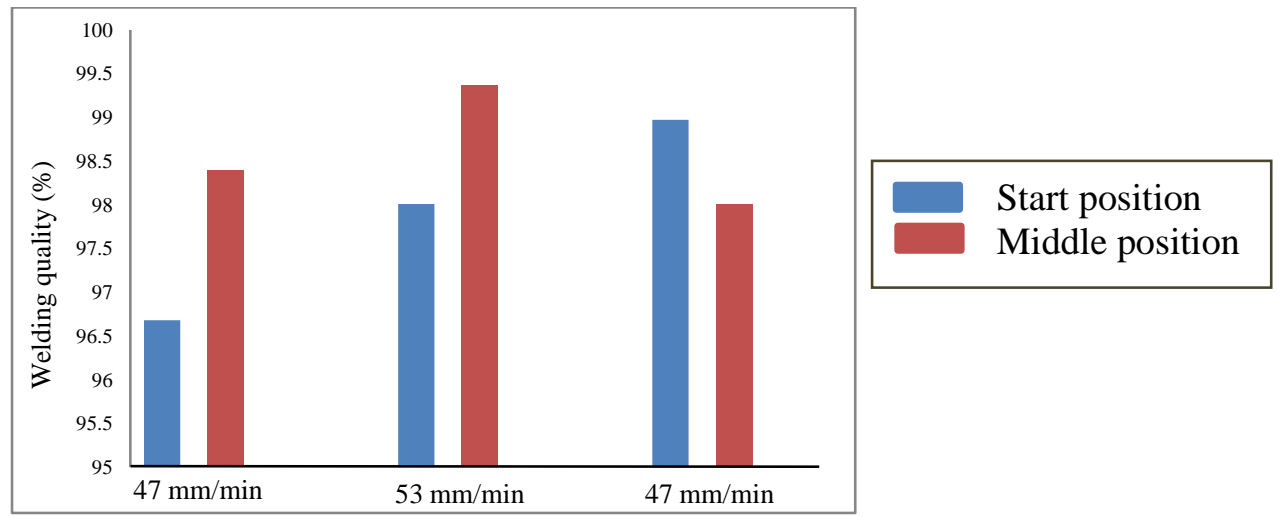

Fig. 8: Welding quality comparison of welding speed at $47,53,60 \mathrm{~mm} / \mathrm{min}$.

\subsection{Verification of the developed algorithm for optimal welding speed}

To verify the developed MD algorithm, the optimal welding speed setting at $53 \mathrm{~mm} / \mathrm{min}$ was employed to quantify the welding quality on the vertical-position welding process. The welding position for analysis is shown in Figure 9, and the experimental data were taken 4 second in every position (point 1 as the start position and point 2 as the middle position) which is 2 second before and after.

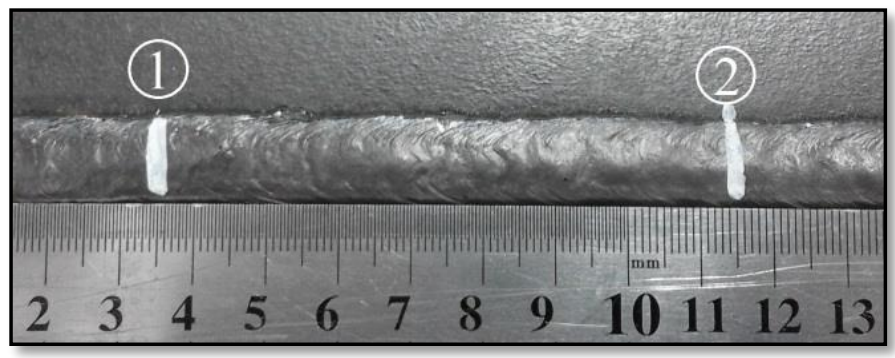

Fig. 9: The positioned of data selection for analysis. 


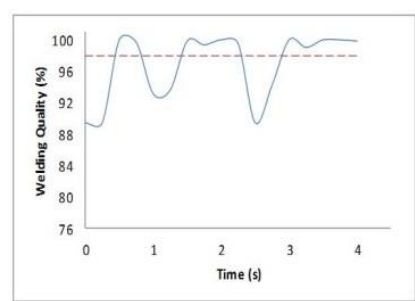

(a) Welding quality at start position

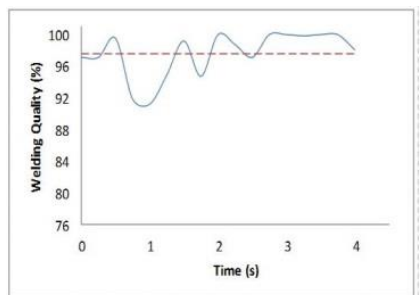

(d) Welding quality at middle position

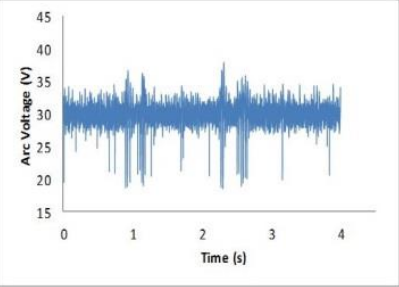

(b) Arc voltage waveform at start position

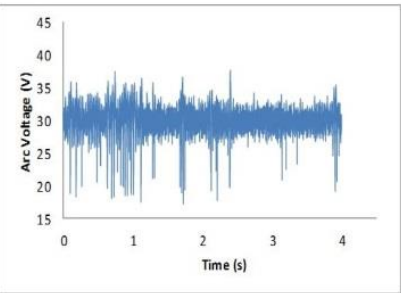

(e) Arc voltage waveform at middle position

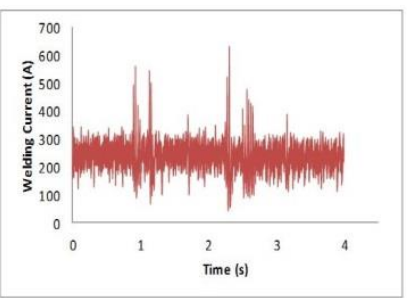

(c) Welding current waveform at start position

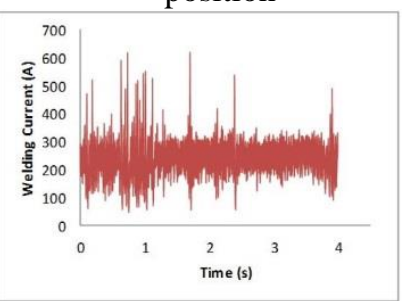

(f) Welding current waveform at middle position

Fig. 10: Welding speed setting at $53 \mathrm{~mm} / \mathrm{min}$.

The developed algorithm was used to analyse the transformed welding current and arc voltage to define the welding fault, and then the welding quality quantified from welding fault data whereby the welding quality quantification was calculated in every $0.25(\mathrm{~s})$. The average welding qualities were indicated by dash line in Figure $10(\mathrm{a})$ and (d) which welding quality values are $97.96 \%$ for the start position and $97.58 \%$ for the middle position. The welding current and arc voltage has significant effect on the welding quality as can be seen in Figure 10 whereas the fluctuations of welding current and arc voltage waveforms in Figure 10(a) and (b) at around 0.75(s) to 1.25(s) lead to the welding quality declined in Figure 10(a) at about $0.75(\mathrm{~s})$ to $1.25(\mathrm{~s})$. It means that more fluctuation in wave length of welding current and arc voltage waveforms will create the welding quality more decreased. The welding fault will take place as the fluctuations in wave length occurred and thus, the welding quality decreased. Since the welding current and arc voltage waveform are affected by the welding speed as input parameter, it must control the welding speed using on-line monitoring system to achieve the desired welding quality.

Detection of welding fault on the on-line monitoring system involved the welding current and arc voltage waveform whereby the analysis employed those output parameters for welding process. It's mean that welding quality doesn't depend on one output parameter, but depend on both output parameters. Therefore, the developed algorithm offers a solution that could analyse both the welding current and arc voltage waveform at once which is proved to define the welding quality. The output parameters from the developed algorithm can be used as a feedback to control welding speed to achieve the desired welding quality during vertical-position welding process. It can be concluded that the developed algorithm has significantly important to control the welding quality during the welding process which is proved by the verification results.

\section{Conclusions}

The optimization of welding speed employed the developed algorithm to quantify the welding quality on GMA vertical welding process has been done in this study and the following conclusions have been drawn:

(1) The best welding quality was achieved $98.01 \%$ for the start position and $99.36 \%$ for the middle position with the optimal welding speed at $53 \mathrm{~mm} / \mathrm{min}$. The welding quality of the welding speed of the start and middle position at $47 \mathrm{~mm} / \mathrm{min}$ and $60 \mathrm{~mm} / \mathrm{min}$ are $96.68 \%, 98.39 \%, 98.97 \%$ and $98 \%$ in sequence.

(2) The verification of MD using optimal welding speed setting was gained the welding quality $97.96 \%$ for the start position and $97.58 \%$ for the middle position. For GMA vertical welding application, the developed algorithm is a novel method that could be applied as a core of welding control to achieve the expected welding quality by manipulating the welding speed.

\section{Acknowledgments}


This research was supported by Basic Science Research Program through the National Research Foundation of Korea(NRF) funded by the Ministry of Education (No. 2015R1D1A3A01020246).

\section{References}

[1] S. P. Tewari, A. Gupta, and J. Prakash, "Effect of welding parameters on the weldability of material," International Journal of Engineering Science and Technology, vol. 2, no. 4, 512-516, 2010.

[2] Z. Huilin, W. Changiian, Y. Xuemei, W. Xinsheng, and L. Ran, "Automatic welding technologies for long-distance pipelines by use of all-position self-shielded flux cored wires," Natural Gas Industry, no 1, pp. 113-118, 2014.

[3] G. Yongdong, Z. Haiyan, and Z. Hongzhou, "The Application of automatic welding technology in West-to-East gas pipeline project," Oil Gas Storage Transp., vol. 22, no. 12, pp. 53-55, 2013.

[4] W. Rui and R. Guo, "Developments of automatic girth welding technology in pipelines," Electr. Weld Mach., vol. 41 no. 9, pp. 53-59, 2011.

[5] H. Anxin, X. Su, and S. Huafeng, "Current situation of automatic welding of domestic long distance pipelines," Natural Gas Oil, vol. 24, no. 2, pp. 12-14, 2006.

[6] L. Helin, L. Ji, and T. Wei, "High grade line pipe and high pressure transportation: significant progress of oil \& gas transportation pipeline technology in China," China Eng. Sci., vol. 12, no. 5, pp. 84-90, 2010.

[7] Y. Zhifeng, Z. Wenwei, and Z. Zhihong. "Development trend of China's gas pipeline and relevant technical problem," Oil Gas Storage Transp., vol. 31, no. 5, pp. 321-325, 2012.

[8] L. Helin, L. Ji, and T. Wei, "Significant technical progress in west-east gas pipeline projects line one and two," Natural Gas Industry, vol. 30, no. 4, pp. 1-9, 2010.

[9] D. W. Cho, S. J. Na, Cho, M. H. Cho, and J. S. Lee, "A study on v-groove GMAW for various welding positions," Journal of Materials Processing Technology, vol. 213, no. 9, pp. 1640-1652, 2013.

[10] I. S. Kim, J. H. Lee, J. P. Lee, M. H. Park, C. K. Park, and Y. S. Kim, “A Study on welding quality of pipe in overlay welding process using Mahalanobis Distance method," Muan-gun, Mokpo National University, 2015.

[11] F. Shengqiang, O. Hiroyuki, T. Hidennori, K. Yuichi, and H. Shengsun, "Qualitative and quantitative Analysis of GMAW welding fault base on Mahalanobis Distance," International Journal of Precision Engineering and Manufacturing, vol. 12, no. 6, pp. 949-955, 2011.

[12] R. R. Chand, "A study on experimental and numerical studies on mecahnical characteristics for multi-pass GMA Welding" Master thesis, Dept. Mech. Eng., Mokpo National Univ., Mokpo, Korea.

[13] S. W. Simpson and X. Li, "Parametric approach to positional fault detection in short arc welding," Science and Technology of Welding and Joining, vol. 2, no. 14, pp. 146- 151, 2009.

[14] S. Adolfsson, A. Bahrami, G. Bolmsjo, and I. Claeson, "On-line quality monitoring in short-circuit gas metal arc welding,” Welding Journal, vol. 2, no. 78, pp. 59-73, 1999.

[15] M. Toshio, T. Hidenori, O. Hiroyuki, and K. Yu-ichi, "Developments real-time monitoring method of welding," Transaction of JWRI, vol. 39, no. 2, pp. 369-371, 2010.

[16] K. Muzaka, M. H. Park, J. P. Lee, B. J. Jin, D. H. Kim, and I. S. Kim, “A study on predictionof vertical-position welding using mahalanobis distance method," International Journal of Innovative researh in Engineering \& Management, vol. 3, no. 3, pp. 154-159, 2016.

[17] P. Satiya, S. Aravindan, P. M. Ajith, B. Arivazhagan, and A.N. Hag, "Microstructural characteristics on bead-on-plate welding of AISI 904L super austenitic stainless steel using gas metal arc welding process," International Journal of Engineering, science and Technology, vol. 2, no. 6, pp. 189-199, 2010. 